\title{
OS ESPARTILHOS SOCIAIS NA COLUNA "PALESTRAS FEMININAS” DE ADELINA AMÉLIA LOPES VIEIRA, NO PERIÓDICO A SEMANA
}

CRUZ, Eduardo da ${ }^{1}$

ABREU, Sérgio ${ }^{2}$

RESUMO: Pretende-se neste artigo analisar a colaboração de Adelina Amélia Lopes Vieira (18501923) no periódico A Semana (1885-1895). A escritora portuguesa residente no Brasil manteve no jornal uma coluna intitulada "Palestras Femininas", na qual comentava assuntos que considerava importantes às mulheres da época, quer em textos ficcionais quer não. Debruçamo-nos nestes escritos com o objetivo de entender o que a autora valorizava sobre perfis femininos de sua época. Percebe-se na análise desses artigos a pressão dos espartilhos sociais sobre as mulheres e sobre a própria escrita de Adelina Lopes Vieira.

PALAVRAS-CHAVE: Imprensa periódica, contos, escritoras portuguesas, história das mulheres

\section{THE SOCIAL SPARKS ON ADELINA AMÉLIA LOPES VIEIRA'S COLUMN “PALESTRAS FEMININAS”, IN THE NEWSPAPER $A$ SEMANA}

\begin{abstract}
It is intended in this article to analise the collaboration of Adelina Amélia Lopes Vieira (1850-1923) in the newspaper A Semana (1885-1895). This Portuguese woman author wrote a column entitled "Palestras Femininas" in which she commented about what she considered important subjects related to the women of that time, either in fictional and non-fictional texts. We take these texts as basis
\end{abstract}

\footnotetext{
${ }^{1}$ Professor de Literatura Portuguesa da UERJ, bolsista PQ2 do CNPq, coordenador do projeto "Escritoras Portuguesas na imprensa periódica do Brasil” (CNPq Processo: 405146/2018-3), doutor em Literatura Comparada (UFF, 2013). eduardodacruz@gmail.com

2 Mestre em Letras - Literatura Portuguesa pela UERJ (2020), licenciado em Letras pela UFRRJ. abreusergi@gmail.com

Jangada | nr. 16, jun/dez, 2020 | ISSN 2317-4722

40 | Pá g in a
} 
to understand what the author valued about the feminine profiles of her time. It can be seen in the analysis of these articles the pressure of social corsets on women and on the author's work.

KEYWORDS: Periodical press, short stories, Portuguese women authors, history of women

Fallando, a sua voz dominadora delicia, e arrebata de improviso; no entanto a bocca rubra e encantadora poucas vezes se entre-abre num sorriso.

São só as cordas da harpa, confidentes d'essa tristeza infinda... esse mysterio! e acompanhando o seu cantar sidereo, soluçam doloridas e frementes. (Adelina A. Lopes Vieira, "Desesperança")

\section{UMA SENHORA ESCRITORA}

Adelina Amélia Lopes Vieira nasceu em Lisboa, na freguesia da Encarnação, em 20 de setembro de 1850, filha de Valentim José da Silveira Lopes e Adelina Pereira Lopes, com quem se mudou para o Brasil aos 6 anos. Ela foi escritora e educadora no Brasil durante mais de três décadas. Além dos livros que publicou, seus textos podem ser encontrados em diversos periódicos e almanaques brasileiros e portugueses. Todavia, chama a atenção seu prestígio no Oitocentos e seu apagamento na posteridade.

Encontramos diversos textos da autora, sobretudo poemas, em jornais dos dois países de língua portuguesa, possivelmente por seu duplo lugar de escritora portuguesa residente no Brasil, que a vinculava aos dois sistemas literários, ainda muito próximos no século XIX. Sua qualidade de escritora foi valorizada no eixo luso-brasileiro, tendo tido grande destaque em sua época, aparecendo aclamada na imprensa, inclusive juntamente com seu coetâneo Machado de Assis $^{3}$. Porém, para a posteridade, sua história e obra caíram em um silêncio pouco compreendido, às vezes retomada, em estudos mais recentes, apenas como coautora de um livro

\footnotetext{
${ }^{3}$ Adelina Amélia Lopes Vieira foi jurada em concurso de sonetos, em 1885, juntamente com Machado de Assis e Lúcio de Mendonça. (A Semana a.I n. 37, 12/09/1885, p. 3)

Jangada | nr. 16, jun/dez, 2020 | ISSN 2317-4722

41 | Pá g i n a
} 


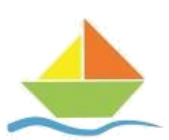

destinado às crianças que escreveu com sua irmã, cada vez mais estudada, Júlia Lopes de Almeida.

O cenário fértil que a irmã ${ }^{4}$ de Adelina Lopes Vieira encontra hoje nos estudos literários também são importantes para que entendamos o contexto no qual Adelina cresceu e viveu na casa dos pais. Júlia Valentim da Silveira Lopes nasceu em 1862 e, por ter uma saúde frágil, não frequentou escolas, tendo como professora a própria mãe e a irmã mais velha. Júlia tornou-se uma personalidade importante por sua produção romanesca, mas o ambiente no qual cresceu era propício à arte, como destaca Elenita Manchope $(2016)^{5}$, o que teria engrandecido a formação cultural das duas irmãs.

De acordo com os relatos de Margarida, Júlia não foi uma criança com muita saúde, por isso não frequentou escolas e aprendeu a ler e escrever com sua irmã mais velha, Adelina. Filha de Dr. Silveira Lopes, médico do mais importante teatro da cidade, teve a oportunidade de assistir [a] artistas de renome mundial. O fato de ser filha de pais com elevado nível cultural possibilitou que Julia crescesse num meio favorável para despertar todo o seu talento.

A família costumava realizar saraus em sua residência, onde sua mãe e a irmã Adelaide cantavam e a irmã Adelina recitava versos de Tomas Ribeiro e Bulhão Pato, a irmã Maria José tocava piano e Julia apenas ouvia. (MANCHOPE, 2016, p. 149-150)

Apesar da diferença de idade entre as duas irmãs, Adelina e Júlia estavam inseridas no mesmo contexto familiar de constante circulação artística. Os saraus em casa eram um ambiente frutífero para a escrita das mulheres, pois seus textos circulavam manuscritos e oralmente ${ }^{6} \mathrm{em}$

\footnotetext{
${ }^{4}$ Adelina teve quatro irmãs e um irmão, pois o registro de óbito de sua mãe, a Viscondessa de S. Valentim, que faleceu a 26 de fevereiro de 1895, indica que ela deixou seis filhos: Adelina Amélia Lopes Vieira, Maria José Lopes Duque, Valentim José da Silveira Lopes, Adelaide Lopes da Silveira de Sena Gonçalves, Júlia Lopes de Almeida e Alice Lopes Campeão (Brasil, Rio de Janeiro, Registro Civil, óbitos, fl. 134, n. 152).

${ }^{5}$ A pesquisadora teve acesso ao espólio pessoal de Julia Lopes de Almeida cedido pela família remanescente.

${ }^{6}$ A pesquisa na imprensa periódica de Campinas, a partir da Hemeroteca Nacional Digital, nas décadas de 1860 e 1870 , revela informações sobre festas e eventos culturais realizados naquela cidade. Adelina recitou poemas num sarau da "Sociedade Terpsichore Familiar" no dia 22 de dezembro de 1869 (Gazeta de Campinas a. I n. 17, 25 de dezembro de 1869, p. 2). Ela também, "que dispõe de vocalisação facilima para dominar as custosas nuences da arte, (deixem o termo profano) e expressar muito sentimento ao pé de muita eschola", cantou a ária "Eleonora Dori", de G. Baptista, num sarau literário e musical realizado no dia 15 de março de 1870, ocorrido no salão da casa de D. Maria Egydio de Souza Aranha e organizado por senhoras em favor de um hospital que o padre Joaquim José Vieira pretendia construir. (Gazeta de Campinas a. I n. 41, 20 de março de 1870, p. 1-2).
}

Jangada | nr. 16, jun/dez, 2020 | ISSN 2317-4722

42 | P á g i n a 


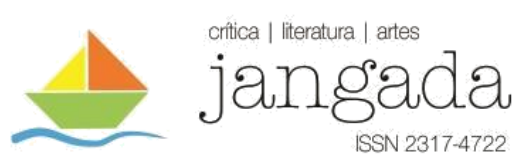

um ambiente semiprivado entre os frequentadores daquelas reuniões, além de haver ali uma rede de sociabilidade formada por pessoas que apreciavam e faziam parte de meios intelectuais e artísticos.

O pai de Adelina, Valentim da Silveira Lopes, interessava-se pela ajuda humanitária e pela educação. Ele foi proprietário e professor do Colégio de Humanidades na rua do Lavradio ${ }^{7}$, no Rio de Janeiro, depois em Friburgo (RJ), tendo também morado com a família em Macaé (RJ) e em Campinas (SP). Algumas informações sobre a família foram publicadas pelo jornal da colônia portuguesa, o Portugal Moderno, destacando ser uma família de intelectuais apresentando, além do médico e das duas filhas escritoras, Adelina Amélia Lopes Vieira e Júlia Lopes de Almeida, o poeta português, marido de Júlia, Filinto de Almeida.

O sr. Viconde de São Valentim, Médico abalisado e distinctissimo é um portuguez de raça que, no Brasil onde firmou domicílio, tem sabido honrar e dignificar o glorioso nome de Portugal.

Em Campinas, no Estado de São Paulo, onde por muitos anos morou, o sr. Visconde de S. Valentim firmou o seu nome de médico juntando-o ás obras mais beneméritas e mais filantrópicas d'aquella terra.

Trabalhando como um apostolo na obra santa da sciencia o sr. Visconde de S. Valentim, na sua larga clinica, nunca soube differençar o doente humilde e pobre do doente rico e poderoso: a todos tratava com a mesma solicitude e com o mesmo carinho.

Por longos anos, dia a dia, foi médico da Misericordia de Campinas e da Sociedade Portugueza da Beneficencia n'aquela cidade, sem receber um vintém do seu trabalho n'estas casas de caridade. (Portugal Moderno, a. VI n. 281, 29 de abril de 1905, p. 2).

Dessa forma, ter um pai intelectual, que se preocupava com as desigualdades sociais, a saúde e a educação, eventualmente possibilitou a Adelina maior liberdade de instrução naquela sociedade patriarcal do século XIX. Além disso, o Visconde de S. Valentim era amigo

\footnotetext{
${ }^{7}$ Oséas Hegesipo de Bulhões Pitanga faz publicar em $O$ Portuguez seu relato de gratidão por ter sido salvo ao ser levado para ser tratado pelo dr. Valentim Silveira Lopes no Colégio Humanidades na rua do Lavradio. $(O$ Portuguez a.III n. 13, 12 de fevereiro de 1863, p. 4).
}

Jangada | nr. 16, jun/dez, 2020 | ISSN 2317-4722 
de Antônio Feliciano de Castilho ${ }^{8}$, que foi um dos maiores apoiadores da escrita de mulheres em Portugal em seu tempo 9 .

Com esse apoio familiar, Adelina Vieira pôde estudar e se formou professora, tendo atuado por mais de três décadas no ensino público do Rio de Janeiro. Durante toda a vida, a escritora se mostrou preocupada com a criação e a formação das crianças. Ela foi uma defensora da educação e seus textos nos apontam não só para sua preocupação com a infância, mas também com as mães que, naquela época, tinham filhos muito cedo, às vezes sem nenhuma instrução ou conhecimento sobre os cuidados que deveriam ter com as crianças.

Buscando informações acerca da vida pública de Adelina Vieira em periódicos do século XIX, a mais antiga menção que encontramos é de 1869, a qual informa que "recitou ao piano duas magníficas poesias de Soares Passos e T. Ribeiro, a exma. Sra. D. Adelina A. Lopes Vieira, com talento e conhecimento literário invejáveis. A recitação esteve na altura daqueles dous divinos poetas.” (Gazeta de Campinas, a. 1 n. 17, 25 de dezembro de 1869, p. 2).

Além de notas sobre suas aparições em eventos públicos de caráter cultural e da publicação de seus textos dispersos na imprensa periódica brasileira e portuguesa, a pesquisa na imprensa periódica também revela a ocorrência de anúncios a respeito de seus livros publicados em volume: são dois de poesia, Margaritas (1879) e Pombal (1880); um de contos, Destinos (1900); e Contos infantis (1886), em parceria com a irmã Júlia Lopes de Almeida.

Foi justamente na imprensa, a partir de pesquisas anteriores, que nos deparamos com o nome de Adelina Lopes Vieira. Sua menção é recorrente em uma série de periódicos que a valorizavam como poetisa, como professora, como filantropa. Pesquisamos na Hemeroteca Digital Brasileira uma série de possíveis nomes que pudessem ser compatíveis com o da autora $^{10}$. Os resultados que encontramos ajudaram a traçar seu perfil biográfico e a reunir seus textos que estavam dispersos.

\footnotetext{
${ }^{8}$ Valentim José da Silveira Lopes encomendou uma missa em homenagem a morte de D. Ana Carlota Xavier Vidal de Castilho, esposa de Antônio Feliciano de Castilho e comentou a proximidade entre eles. (Gazeta de Notícias, a. 2 n. 176, 27 de julho de 1871, p. 2). Além disso, sua tese apresentada à Faculdade de Medicina da Bahia em 1867 traz agradecimentos aos dois irmãos Castilhos: "Ao meu bom mestre e amigo, o illustrissimo e excelentissimo senhor Dr. Antonio Feliciano de Castilho, principe dos poetas contemporaneos portuguezes: dívida sagrada de amisade" e "Ao me generoso protector, o illustrissimo e excelentissimo senhor conselheiro Dr. José Feliciano de Castilho Barreto e Noronha, assombroso ornamento do mundo litterario: protesto sincero de gratidão" (LOPES, 1867).

${ }^{9}$ É possível verificar esse apoio em estudos de Ana Cristina Comandulli da Cunha (2014) e Eduardo da Cruz (2017).

${ }^{10}$ Adelina Lopes Vieira; Adelina Amelia Lopes Vieira; A. A. Lopes Vieira; Adelina A. Lopes Vieira; Adelina A. L. Vieira; Adelina Vieira; Adelina Lopes.
} 
Dentre os escritos reunidos, uma coluna publicada no periódico A Semana (1885-1895) intitulada "Palestras Femininas" fez-se importante por destacar o que a autora destacava como temáticas propícias às mulheres. Ela era responsável naquele periódico por uma voz direcionada às leitoras, o que hoje podemos entender como uma boa estratégia para aumentar assim o público consumidor de A Semana.

Sabemos que a imprensa voltada para mulheres, controlada por elas ou com espaço para seus textos, era um dos principais redutos para a circulação da produção de autoria feminina no eixo Brasil-Portugal. Uma autora podia mandar uma carta com um pequeno poema, um conto ou algum comentário para algum jornal sem gerar muitos custos e sem precisar sair de casa. Lembremos que a publicação de obras em volumes naquela época custava muito caro e, desta forma, menos comum para as mulheres. A publicação em um periódico ou almanaque apenas dependia que o redator ou a redatora gostassem do tex to ${ }^{11}$. No caso de livros, era comum que as mulheres necessitassem de autorização de um homem da família (pai, marido, ou mesmo filhos adultos) e costumavam vir com um prefácio de algum escritor endossando a publicação por ser de mulher.

Nesse contexto, escritos produzidos por mulheres no século XIX carregam neles muito mais do que o início da emancipação, são registros diretamente produzidos por aquelas que conseguiram preencher espaços que antes não ocupavam. Tais documentos são importantes para entendermos principalmente como pensavam e com o que se importavam.

Posto isso, a coluna "Palestras Femininas" escrita por Adelina Vieira é um tipo de texto de opinião e exibe uma autora, por vezes, livre de uma persona literária, por se tratar muitas vezes de textos não ficcionais. Talvez seja o mais próximo que possamos chegar de seus posicionamentos. Em seguida, analisaremos essas colunas para verificar o que a escritora destacava enquanto representação, temática e comportamentos femininos.

\section{ADELINA VIEIRA E SUAS PALESTRAS FEMININAS}

\footnotetext{
${ }^{11}$ Essas considerações são baseadas no que Vanda Anastácio explica no caso de colaborações femininas para almanaques: "A «facilidade» de acesso à publicação assim proporcionada pelo almanaque, associada ao facto de este ser encarado como um objecto distinto do livro, menos prestigiado e menos exigente que aquele, tornou-o numa via de acesso à imprensa e ao reconhecimento do público especialmente adequado à produção escrita das mulheres, numa época em que, apesar de ser já significativa a percentagem de elementos do sexo feminino alfabetizados, se lhes exigia modéstia, discrição e o confinamento à esfera doméstica.” (2012, p. 67).
} 


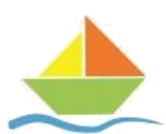

Apesar de ter publicado textos em diversos periódicos, a colaboração de Adelina Lopes Vieira que mais nos chamou atenção, pela constância, foi a d'A Semana. O jornal tinha como redatores Valentim Magalhães e Filinto de Almeida (que se tornou cunhado de Adelina ao se casar com Júlia Lopes). As colunas mesclavam artigos de opinião e textos literários, mas ambos caminhavam na mesma direção temática que era uma ideia de aprendizado pelo exemplo.

A coluna parece ter obtido muito sucesso com as mulheres da época, fazendo com que Adelina Lopes Vieira fosse convidada para publicar textos com o mesmo título, anos mais tarde, no periódico A Mensageira (a.1 n.2, 30 de outubro de 1897, p. 31), o que acabou por não se concretizar. Contudo, n'A Semana, foram publicadas 16 "Palestras Femininas"12 entre 1886 e $1887^{13}$, com temas variados de debate e alguns contos, sem contar outros textos de Adelina Vieira que saíram nesse periódico além dessa rubrica.

Interessante refletirmos sobre o papel social de A Semana, pois foi um periódico publicado a partir de 1885 e tinha como objetivo apresentar fatos, segundo seu redator Valentim Magalhães, de forma imparcial, mas foi muito além disso, tornando-se um "importante instrumento de intervenção social” (CERNIC RAMOS, 2012, p. 1). A revista contava com notícias políticas, literatura, comércio etc., mas a imparcialidade talvez não fizesse realmente parte de sua pauta. Nos anos que se seguiram a 1885, o periódico foi uma importante voz em defesa do abolicionismo e, por isso, é difícil associar seus colaboradores, incluindo Adelina Amélia $^{14}$, a pensamentos contrários a esses ideais, tão patentes nessa folha.

Cabia, então, à imprensa, não a "neutralidade", a notícia dos fatos, mas servir de impulso da "consciência pública", mobilizando forças em nome de um projeto que, naquele momento, representava a emancipação dos escravos sexagenários e, principalmente, uma batalha contra a escravidão. Luís Murat, parceiro do abolicionista José do Patrocínio em diversas empreitadas jornalísticas, ao escrever para a coluna semanal "Política e Políticos",

\footnotetext{
${ }^{12}$ As referências a essas colunas encontram-se todas indicadas neste artigo.

${ }^{13}$ A Hemeroteca Nacional Digital possui até o número duplo 169-170, de 21 de abril de 1888, depois retoma a partir do número 1, de 5 de agosto de 1893. No entanto, essa retomada da publicação em 1893 indica uma passagem de propriedade da revista em 31 de outubro e uma despedida em 7 de novembro de 1888. Isso quer dizer que há edições que não constam digitalizadas, entre abril e novembro de 1888 pelo menos. É possível que nesses números houvesse outras colaborações de Adelina Lopes Vieira.

${ }^{14}$ Importa destacar que Adelina Amélia Lopes Vieira também tem um perfil abolicionista, tendo composto poemas para serem declamados em celebração pelo fim da escravidão e publicados em A festa das creanças: comemoração da lei de 13 de maio que aboliu a escravidão no Brazil, de 1888.
}

Jangada | nr. 16, jun/dez, 2020 | ISSN 2317-4722

46 | P á g i n a 


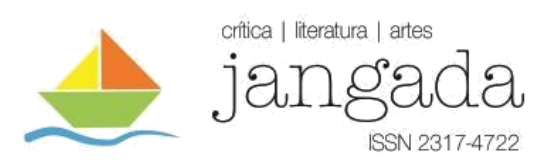

certamente tinha consciência do papel que aqueles textos ocupariam n'A Semana. Para a revista, surgida em contexto tão conturbado, não parecia possível, ou mesmo desejável, manter-se distante daquele confronto. (CERNIC RAMOS, 2012, p. 4)

Ana Cernic Ramos (2012) aponta já existir em A Semana um delinear abolicionista nas colunas políticas que criticavam duramente o parlamento e a Coroa. Havia uma necessidade de posicionamento da classe intelectual, pois, naquele momento, desde a lei Eusébio de Queiroz (1850), o Brasil passava por fortes discussões acerca dos escravizados e a imprensa era o principal veículo de circulação de ideias.

Adelina Lopes Vieira não tinha uma coluna política, mas fazer parte do corpo de escritores de um veículo importante na formação das mentalidades destaca ainda mais a sua valorização enquanto intelectual em seu tempo. As mulheres que escreviam na imprensa, muitas vezes, buscavam, até então, um modelo que as mantivesse dentro do socialmente permitido.

A imprensa, principal veículo em circulação é usado para dinamizar todas estas ideias, é um dos lugares privilegiados da manifestação do pensamento feminino que luta por uma identidade que lhe era negada pelas estruturas sociais. O jornal é o lugar próprio da manifestação das ideias novas. As posições expressas sobre a instrução que a população feminina devia receber, é fulcral já que nesta questão confluem muitas outras problemáticas e causas, tais como as respeitantes à política educativa, à economia, à mentalidade e à modificação dos usos e costumes. A análise dos conceitos, propostas e realizações acerca da instrução é possivelmente o melhor meio de compreender a transformação de papéis sociais femininos. Na verdade, neste processo de consciencialização, pode ser verificada e avaliada a criação ou não das condições favoráveis à instrução, ao progresso e à intervenção da mulher nas áreas sócias e culturais. (RAFAEL, 2011, p. 46)

O debate dos papéis femininos era fomentado pelos jornais, sobretudo naqueles que contavam com a colaboração de mulheres. Para além da literatura, as escritoras que tinham colunas de opinião em periódicos tinham alguma liberdade para produzirem textos sob uma assinatura muito pessoal. Elas escreviam seus pontos de vista sem a proteção ficcional do texto 


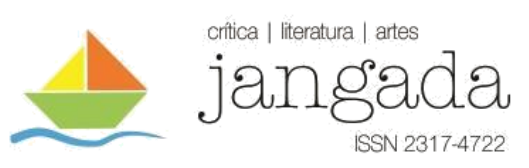

literário. Em muitas dessas colunas havia apontamentos para o bem estar das mulheres em relação aos seus comportamentos perante assuntos que se julgavam importantes para elas, como o casamento e a maternidade.

No século XIX, havia um número considerável de manuais de civilidade que ensinavam a burguesia a viver segundo as normas sociais e, em geral, os textos de Adelina Lopes Vieira em A Semana tinham supostamente esta ideia ao tratar das representações das mulheres, mostrando ali resultados do que deveria ou não ser feito. Como assevera Maria de Lourdes Lima dos Santos,

Precisamente no século XIX, a literatura de civilidade expressa pelos manuais tem provavelmente o seu grande último momento. Hoje em dia, cortesia e civilidade são vocábulos antiquados e os manuais caíram no ridículo. $\mathrm{Na}$ origem, a noção de cortesia tinha um significado bem estrito, designando a forma de as pessoas se conduzirem na corte; os manuais de etiqueta multiplicar-se-iam por altura do alargamento e intensificação da vida de corte que acompanham a crescente centralização política. (SANTOS, 1983, p. 14)

Santos ainda deixa claro que os manuais de civilidade reforçavam os estereótipos da vida familiar e formulavam um modo de pensar e agir que deveria ser adotado em casa. Dessa forma, podemos pensar nos textos de Adelina como essa espécie de manual à vida prática daquelas mulheres voltada ao lar.

A habitação familiar é o reduto, "lar que embala os que tiverem sido magoados
e contristados", lugar donde se sai apenas "quando o dever ordenar".
Num dos M. C., afirma-se expressamente a vocação do compêndio de
civilidade para fornecer "as bases, os alicerces imprescindíveis para construir
a família honesta".
Que bases e alicerces? A civilidade, precisamente, à polidez do coração e das
ações, uma educação moral que é, fundamentalmente, a aprendizagem das
boas maneiras que distinguem. (SANTOS, 1983, p. 25-26)

No primeiro de seus textos publicados em "Palestras", Adelina escreve: "Hoje, para todas as mães que leem A Semana, tenham a ventura de que gosa a minha amada Laura, principiarei a guial-as no modo de educar physica e moralmente os seus anjos do lar - as Jangada | nr. 16, jun/dez, 2020 | ISSN 2317-4722 


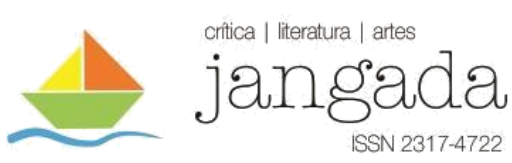

criancinhas." (VIEIRA, A Semana a.2 n.68, 17 de abril de 1886, p. 123). Laura, sua afilhada, havia colocado em sua filha o nome da madrinha para compensar a distância física entre elas. Adelina, por sua vez, descreve no texto várias ações necessárias para conseguir que a criança cresça com saúde e alegra-se de que, a partir daquele momento, todas as mães, leitoras d'A Semana, é claro, teriam essa sorte de tê-la para instruí-las. São diversas indicações, como por exemplo:

Para que o corpo seja são é necessário, primeiro que tudo, que a criança não viva muito agasalhada e que se banhe diariamente em agua fria. Os banhos serão tépidos até um mez de edade, mais ou menos; depois completamente frios, frios mesmo no inverno. Assim, as crianças ficarão alegres e rosadas, e á mesa acharão os bifes sangrentos saborosíssimos, os ovos e o leite deliciosos! Desde a mais terna edade deverão os pequeninos estar pouco cobertos; como as flores, carecem de banhar-se em ar puro; são esses verdadeiros banhos tônicos. Os brincos da primeira infância deverão ser o mais possível ao ar livre. (VIEIRA, A Semana a.2 n.68, 17 de abril de 1886, p. 123)

Adelina Lopes Vieira não foi mãe, mas as mulheres tinham, naquele tempo, uma instrução baseada em serem as primeiras educadoras dos filhos, ademais, a autora era professora e lidava com crianças desde a juventude. Ela frisava a importância das mães e dos pais junto aos filhos:

Oh! Felizes, bem felizes os filhos que podem adormecer com a cabeça pousada no regaço materno, estreitar nos braços um pae amantíssimo e sentirse confortados com a bençam que, de perto ou de longe, lhe lançam os corações dos paes!

A morte de nossos paes é a maior dar dores. Deus vos preserve, leitoras, de tão angustioso transe.

Vós, mães, conservae a vida e a força. Para poupardes a vossos filhos essa infinita agonia. (VIEIRA, A Semana a. 2 n. 92, 2 de outubro de 1886, p. 320321)

Era esperado que em um espaço voltado para mulheres na imprensa houvesse o tema da maternidade, pela pressão social que sofriam para serem boas esposas e mães. Nas "Palestras 


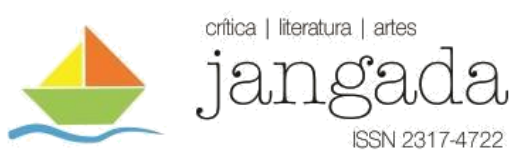

Femininas", Adelina desenvolve uma espécie de curso de pedagogia infantil para melhor conduzir as mães no trato com os filhos. Afinal, com a ascensão da burguesia, as mulheres receberam, na divisão de papéis sociais, essa função. Por isso, Adelina indicava que as crianças fossem desde novas expostas à arte para seu melhor desenvolvimento intelectual. Ela também recomendava os tratamentos que os infantes deveriam receber para seu bem estar físico, já que, no século XIX, ainda existiam negligências com o corpo dos pequenos.

Até os dias de hoje é recorrente o fato da importância dos manuais de comportamento, de saúde e de bem estar como o caso descrito acima. Programas televisivos e jornais ensinam ainda como devemos, por exemplo, lavar as mãos. Tal prática se iniciou no século XIX, quando os médicos higienistas começaram a debater o trato com as pessoas.

Lima e Hochman (1996) destacam a possibilidade de se criar uma ideia de nacionalismo a partir da alfabetização, do serviço militar, da atenção na saúde, do aumento do colégio eleitoral e etc. Dessa forma, a ideia de ensinar às pessoas formas de agir, essa criação do sujeito higienizado, contribuía também como forma de construir o conceito de nação em uma sociedade.

No Oitocentos, o número de filhos ainda era alto e existia aqui significativa mortalidade infantil, além de instituições como a roda dos expostos ${ }^{15}$ e abandonos de crianças pelas ruas. $\mathrm{O}$ entendimento da criança como um ser amado e carismático estava ainda em construção, acompanhando os séculos XIX e XX:

Trata-se um sentimento inteiramente novo: os pais se interessavam pelos estudos dos seus filhos e os acompanhavam com solicitude habitual nos séculos XIX e XX, mas outrora desconhecida. [...] A família começou a se organizar em torno da criança e a lhe dar uma tal importância que a criança saiu de seu antigo anonimato, que se tornou impossível perdê-la ou substituíla sem uma enorme dor, que ela não pôde mais ser reproduzida muitas vezes, e que se tornou necessário limitar seu número para melhor cuidar dela. (ARIÈS, 1973, p. 12)

\footnotetext{
${ }^{15}$ Esta roda era uma espécie de dispositivo onde eram colocados os bebês abandonados por quem desejasse fazêlo. Apresentava uma forma cilíndrica, dividida ao meio, sendo fixada no muro ou na janela da instituição. O bebê era colocado numa das partes desse mecanismo que tinha uma abertura externa. Depois, a roda era girada para o outro lado do muro ou da janela, possibilitando a entrada da criança para a instituição. Prosseguindo o ritual, era puxada uma cordinha com uma sineta pela pessoa que havia trazido a criança, a fim de avisar o vigilante ou a rodeira dessa chegada, e imediatamente a mesma se retirava do local (PASSETI, s/a, p. 9).
} 
Com base nessa nova percepção da criança pela sociedade, em outra "Palestra", Adelina defende a existência do intelecto infantil. A autora justifica suas sugestões de prática para com as crianças citando Locke, Fenelon, Pe. Girard, Mme. Necker, Herbert Spencer e Perez, e pondera que "é brincando que os pequenos revelam muitas vezes as suas inclinações. Fenelon diz mais 'o nosso papel deve limitar-se a observal-os com rosto alegre e moderar-lhes os enthusiasmos quando exaggerados." (VIEIRA, A Semana a. 2 n. 99, 20 de novembro de 1886, p. 375-376).

A pedagogia é algo tão forte em seus textos que ela chega a se desculpar pela repetição do assunto. Por outro lado, se pensarmos que ainda hoje professores são expostos todos os dias a problemas advindos da estrutura familiar, para uma professora primária, como era o caso de Adelina Vieira, poder fazer algo que estivesse ao seu alcance e que ajudasse mães e crianças deveria ser gratificante.

As maiores alegrias de uma casa são as crianças e as flores. Infelizes os que não podem ou não sabem assistir ao desabrochar d'essas duas odorosas criaturas existências!

Como deve ser insípida, triste mesmo, uma habilitação sem jardim, sem um quadradinho de terra, onde se possa ao menos cultivar, ao menos uma roseira?! Flores! Muitos vos cultivam, mas nem todos vos entendem. (VIEIRA, $A$ Semana a.2 n. 79, 3 de julho de 1886, p. 214)

No trecho acima, Adelina comenta sobre a simbologia das flores e as compara às crianças. Do ambiente do lar, da instituição familiar, para sua coluna, pode entender-se um jardim com flores as quais as mulheres deveriam regar e cultivar para o bem viver. Flores normalmente nos levam à sensação de bem estar e à necessidade de cuidado para seu crescimento.

É comum na obra da poetisa também simbolizar as mulheres por flores, talvez por uma questão de delicadeza, mas as flores, como a própria Adelina conclui, serviam de representação para tudo: da infância, da vida, do casamento, da morte. Comparar mulheres a flores revela 
muito mais do que um símbolo de pureza e delicadeza, era também um símbolo de resignação ${ }^{16}$ e adaptabilidade.

Esses modelos que fazem parte daqueles manuais de civilidade que eram as "Palestras Femininas" geram para nós a problemática da visão que uma mulher teria sobre si mesma, pois, como já indicamos, os papéis femininos na sociedade do Oitocentos eram pré-estabelecidos e, por isso, não era permitido que suas temáticas fugissem demais do esperado. No século XIX, as mulheres eram muitas vezes consideradas como seres sem intelecto, que deveriam se concentrar em desempenhar seus papéis como esposa e mãe. Os manuais de comportamento e até mesmo os médicos confirmavam essa afirmação:

Com um organismo débil (órgãos delicados, uma estrutura óssea fraca, tecidos moles e esponjosos, nervos bastante ramificados o que explicaria a grande sensibilidade e o predomínio da emoção sobre a razão), sujeita a indisposições periódicas que condicionam a sua instabilidade humoral, a mulher é considerada, no século XIX, como possuindo uma fisiologia patológica. Comprovaria esta fragilidade a falta de auto-controle, o que convertia a mulher num ser a proteger. (VAQUINHAS, 2000, p. 22)

Nesse contexto, as colunas de Adelina Vieira seguem o socialmente aceito. Sem se aproximarem de uma tentativa feminista, elas reforçam e refletem a mentalidade daquele tempo. Por exemplo:

O lar é o império da mulher; ali é completo o seu domínio, e um encanto o ser vassalo.

Mas nem todos os lares prendem, nem todas as mulheres sabem attrahir e encantar.

Algumas conheço eu, (infelizes!) que se queixam com amargurado que os maridos prefiram passar os domingos em casas de estranhos, nos clubes e hotéis do arrabalde, a passal-os no aconchego da família.

\footnotetext{
${ }^{16}$ Adelina, na nota inicial de seu primeiro livro, Margaritas (1878), usa essa palavra para qualificar suas margaritas.
} 


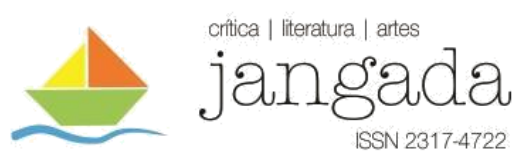

Têm razão, mas, pobresinhas, não comprehendem que são ellas as principaes culpadas d'esse desapego do lar. (VIEIRA A Semana a.2 n. 7, 15 de maio de 1886, p.156)

O trecho acima funciona como um guia para que os maridos se interessassem por estar em casa com suas esposas, como se fosse das mulheres o dever do bem estar do esposo, pois eles eram livres e elas, presas ao lar. Pode parecer estranho para os leitores do século XXI, que tanto debate questões feministas, ter contato com textos mantenedores da imposição de subserviência para as mulheres de outrora, ainda mais quando elas próprias reforçam o conservadorismo em seus posicionamentos, mas isso é causado pela internalização da dominação masculina sobre corpos e mentes das mulheres, como explica Bourdieu (2014). Por isso, a colunista insiste no papel da esposa na manutenção do lar:

Fitou-me um instante e perguntou-me admirada: - "o que faço eu, para que ele se aborreça da minha companhia?" - Nada, respondi; e eis ahi o teu erro. Se toda a semana trabalhasses, para que nas poucas horas em que teu marido está em casa, o seu olhar repousasse, com a satisfação, sobre tudo que o rodeasse; se tudo fosse bello, asseiado, harmônico: se as flores estivessem artisticamente dispostas nos vasos [...]

Experimenta: ergue-te cedo, lida um pouco mais, e verás que não canças, antes se te apagarão essas olheiras, que a tristeza e o tédio desenharam no teu rosto, minha gentil desalentada de vinte anos! (VIEIRA, A Semana a.2 n.7, 15 de maio de 1886, p.156)

Não podemos nos deixar cair na falsa ideia de apontá-la pelo seu conservadorismo e sim nos atentemos àquela tentativa de melhorar, da maneira que fosse, a vida de mulheres que comumente eram obrigadas a se casar com pouca, ou nenhuma, experiência para lidarem com uma vida adulta. Essa rede de apoio era importante e talvez emancipatória, pois dava às mulheres a possibilidade de estar em contato, mesmo que indiretamente, com um grupo que a entendesse. É o que se nota em outras colunas de sua autoria.

Meses mais tarde, Adelina publica em uma "Palestra" um conto, "Futuros", que narra a história de uma suposta prima e de duas amigas que tentavam prever seus destinos e deixavam claras suas aspirações: 
Ao aproximar-me, ouvi estas palavras de Amelia: "Juro que assim será." e logo as risadas argentinas de Carmem e Albertina, que diziam: "Não jures, isso é impossível; aposto que ainda nos virás pedir que desobriguemos do juramento..."

Cheguei-me então, pedindo para ser ouvida na questão que tanto as affastára de nós a tarde inteira, e Carmem, a mais travessa das três, rindo muito, respondeu-me:

- Imagine que falávamos do futuro, do nosso indeterminado futuro.

- Cor de rosa, não é assim?

- Não sei. Albertina diz que casa e funda a sua felicidade no amor; Amelia diz que não a casará nunca, para viver para os irmãos e pae; eu não caso porque não quero; só aspiro á completa liberdade.

$[\ldots]$

- Eu? [Carmem] Não creio na felicidade que nos encadeia; não terei nunca os pulsos algemados. Que é o esposo? Um senhor; os filhos, que são? Deveres e dores sem termo, torturas sem compensação bastante. Oh! Ser livre, pensar, aprender amar em liberdade! Eis a suprema aspiração da vida. Sou rica e intelligente, de nada mais preciso. Nasci águia, quero elevar-me ás nuvens, sem que o mais tênue fio me prenda as azas, sem saudades da terra. (VIEIRA, A Semana a.2 n. 89, 11 de setembro de 1886, p.294-295)

As decisões da vida adulta das mulheres do século XIX não eram controladas por elas próprias. Por isso, como discussão emancipatória, a autonomia feminina é um dos temas recorrentes em textos de escritoras na literatura portuguesa oitocentista. $\mathrm{O}$ casamento funcionava como uma forma de transferência da responsabilidade sobre as mulheres dos pais para os maridos e, em caso de não se casarem, não havia facilmente a "liberdade", como defende Carmem. No trecho acima, as três moças ansiavam por coisas diferentes, mas suas realidades percorrem outros caminhos. Albertina já era noiva de um belo rapaz e sonhava em viver para o marido e para os filhos, mas o jovem:

uma tarde, depois de, ao lado de Albertina, ter dado mostras de uma paixão incandescente, de ter pedido - como um favor do céo - á noiva a rosa branca que ella prendera á cintura; depois de ter lhe beijado respeitosamente as 


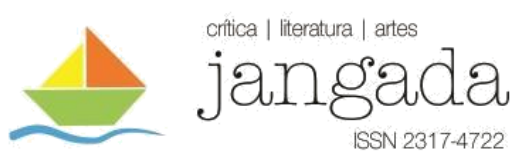

opulentas tranças escuras, comparando-a aos anjos, ás ondinas, ás estrelas; depois de lhe ter jurado uma eternidade de amor, encontrou uma viúva com 50 dezembros, mas também 50 contos que lhe pagou as dividas e o tornou o mais caricato e causticato dos esposos. (VIEIRA, A Semana a.2 n. 89, 11 de setembro de 1886, p. 294-295)

Lopes Vieira mostra que os interesses de homens e mulheres, devido à criação que tinham, eram diferentes. E que a vida dependia de questões mais pragmáticas do que o amor. Dessa maneira, o destino que parecia o mais fácil de se resolver teve outro rumo: Albertina se casou com um rico comerciante de café que odiava e não teve filhos. Já Amélia, “essa - a que mais desmentimos, dando como irrealisavel o seu programa de futuro - foi a única a cumprilo. Da lições de piano e cantos e, nas poucas horas vagas, educa os irmaosinhos. O velho pae já sorri satisfeito ao ouvil-a cantar ou ensinar musica a mais novinha" (VIEIRA, A Semana a.2 n. 89, 11 de setembro de 1886, p. 294-295). Quanto a Carmem:

a liberdade, personificada na mais linda morena que conheço - entregou os pulsos voluntariamente ás algemas que temia. Casou com um advogado celebre, que tem muito talento mas ainda muito mais ciúme. Já tem três filhinhos, sendo os dois primeiros duas lindas meninas gêmeas, que são filhadas de Albertina e Amelia. Não tem um só momento de liberdade a minha irrequieta captiva. (VIEIRA, A Semana a.2 n. 89, 11 de setembro de 1886, p. 294-295)

As vontades daquelas mulheres não foram levadas em consideração quando seus futuros se decidiram. A narradora de Adelina chama atenção, no fim do texto, sobre a questão de ninguém conseguir prever o destino, o que não é mentira, mas ao sexo feminino existia um futuro condicionado. As três mulheres foram levadas ao que se esperaria delas: Albertina casouse com um homem rico, de quem não gostava, mas, mesmo estando em um casamento infeliz, estava casada, como pretendia sua família. Amélia manteve-se dentro de um círculo dominante, pois havia perdido a mãe e a casa precisava de uma mulher que cuidasse de seu funcionamento e, por isso, realizou com facilidade o desejo de não se casar. Carmem, segundo Adelina A. L. Vieira, casou-se por vontade própria, mas sua vida ficara anulada para cuidar da casa e dos filhos. A ocupação da última a impedia de pensar em outra coisa. 


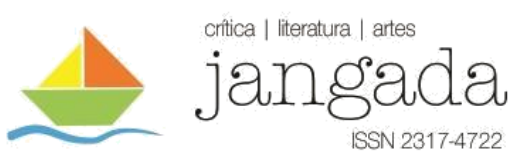

Seguindo o mesmo caminho da condição das mulheres, Adelina traduz e publica em "Palestras Femininas" um conto de Paul Delair, publicado originalmente no livro Les Contes d'à présent avec une lettre de Coquelin Aîné sur la poésie dite em public et l'art de la dire (1884), intitulado "O Xale". Essa narrativa aborda o que se entendia como amor conjugal. Suas palavras que acompanham a tradução indicam que ela não resistiu "a tirar um exemplo claro e bello de abnegação conjugal, do que deve ser o amor de esposa, de um dos belos contos de Paul Delair." (VIEIRA, A Semana a.2 n.94 16 de outubro de 1886, p.335-336). O conto discute um assunto delicado, o adultério masculino. A tradutora sugere que as mulheres ajam da mesma forma que a personagem para a manutenção de seus casamentos.

É na vida conjugal, no modo pelo qual comprehende o papel de esposa e mãe, que a mulher patenteia, a maior parte das vezes, os mysterios do amor que une ou unia seus paes.

Mui raramente veremos esposas bruscas, seccas, intractaveis, grosseiras, se tiveram uns paes amigos, cordatos e affectuosos no tracto conjugal. (VIEIRA, A Semana, a.2 n. 94, 16 de outubro de 1886, p. 335-336)

Resumidamente, o conto traduzido por Adelina Vieira é relativo a um casal de idosos no qual o homem comete um adultério e a esposa é avisada da traição do marido, mas nada faz. A personagem o vê gastando todo o dinheiro que tinham para dar presentes à amante. Como reação, ela diz que trabalharia para ajudá-lo a manter a casa. A esposa fica com pena, pois sabe que a menina jovem o descartaria quando soubesse que seu dinheiro acabara. A idosa ainda afirma ser capaz de consolá-lo caso isso acontecesse. As estruturas familiares conservadoras tentavam ao máximo fazer com que as mulheres entendessem o amor conjugal como a total abnegação feminina em prol do homem.

Paula Morão (2011) esclarece que a imagem da mulher na Literatura do final do século XIX é vista com pessimismo, pois os males sociais e a decadência passam a ser representadas por figuras femininas. As próprias mulheres eram ensinadas a se entenderem de forma que se anulassem em relação aos maridos e, por isso, certos pensamentos eram introjetados à sua própria existência.

Adelina usa o conto como exemplo de comportamento que as mulheres deveriam seguir, reforçando o lugar de subserviência feminina naquela sociedade. No entanto, não podemos esquecer que não havia divórcio ou liberdade de escolha para as mulheres naquela Jangada | nr. 16, jun/dez, 2020 | ISSN 2317-4722 


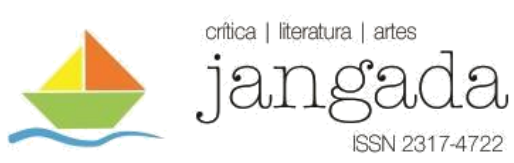

época. Inclusive, sabemos que, se os papéis fossem invertidos na narrativa, seria visto como escandaloso o adultério partindo de uma senhora. $\mathrm{O}$ conto acaba funcionando como um aviso das agruras pelas quais as mulheres poderiam passar, como explica Maria Celeste Andrade (2013):

A erotização das esposas aviva o temor do adultério feminino. Ele é considerado crime para ambos, mas a posição da lei frente ao adultério masculino é afrontosamente diferente. O homem só é levado a tribunal, se, comprovadamente, mantiver uma concubina em domicílio conjugal, pois coloca a família em perigo. $\mathrm{O}$ adultério da mulher, em qualquer circunstância, é crime, sujeito à pena de prisão ou até mesmo de morte, tolerada extraoficialmente, como crime de honra. Em caso de separação, a mulher devia manter-se fiel, o mesmo não sendo exigido do homem, já que, somente o adultério feminino acarretava o risco de fazer com que os bens patrimoniais caiam em mãos de filhos de estranhos. Essa legislação muda entre 1880 e 1914, mas continua por muito mais tempo existindo na prática. (CORBIN, p. 554). Até hoje, em muitos casos. (ANDRADE, 2013, p. 71)

Além de qualquer coisa, Joana, a personagem principal do conto, faz questão de ressaltar que o marido a ama e que não fará nada a respeito do adultério. Apesar de Adelina dividir a opinião do leitor do conto, o texto vai na contramão da ideia de "Amor conjugal" com que intitula essa "Palestra", uma vez que aponta para a necessidade de recalcar o sentimento para agradar o marido. Adelina reforça essa ideia como fórmula para manter o casamento. Dessa maneira, às mulheres, mesmo casadas e dentro de suas casas, não era permitido viver seus amores, seus desejos e suas sexualidades de forma compartilhada no matrimônio. Naquela sociedade moralmente religiosa não cabia essa formulação de pensamento.

O trato das crianças e da vida conjugal leva Adelina a negligenciar outros assuntos em sua coluna, recebendo críticas porque ela não tratava de moda, uma de suas funções em $A$ Semana, já que era a única colaboradora feminina fixa, mas o assunto não parece abalá-la. Lembremos que, apenas na segunda metade do século XX, A Folha de São Paulo leva as reportagens de moda para o caderno de cultura, a Ilustrada, e passa a debater o assunto como comportamento de diferentes grupos e gêneros, tirando o estigma de caderno feminino. Entretanto, naquela época, havia uma necessidade de se escrever sobre esse tema como assunto 


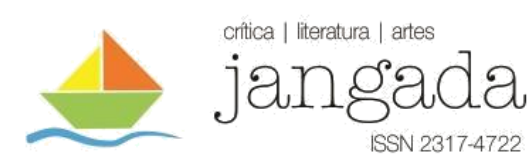

de mulheres, já que, para os homens, este seria praticamente o único tópico que deveria importar a elas, pois os periódicos femininos eram primeiramente publicações sobre moda. Isso só começa a mudar quando

o protagonismo feminino adentra as redações e toma para si a direção política e ideológica de muitas das folhas destinadas às mulheres. De leitoras a redatoras, abrem espaço às vozes femininas antes reclusas às alcovas, e empreendem a transformação hoje perceptível no perfil dessa imprensa: de "revistas de moda" a órgãos de reflexão. (DUARTE, 2016, p. 26)

Em A Semana de 22 de maio de 1886, Filindal ${ }^{17}$, em sua coluna, relata o início da Liga da toilette nacional fundada em Londres pela Viscondessa de Haberton com o intuito de abolir da vestimenta feminina todos os exageros, declarando guerra aos espartilhos que até mesmo lesionavam os órgãos. Filindal encerra o texto dizendo "Demonio! Esquecia-me que a moda tem cá por casa quem trate d'ella, quem a defenda e quem a censure. - Perdão, exma. Sra. D. Adelina Vieira!” (ALMEIDA, A Semana a.2 n. 73, 22 de maio de 1886, p. 1-2). O colunista estava alfinetando-a (para utilizarmos uma expressão sobre moda), pois ela deixava o assunto de lado. A autora das "Palestras", por sua vez, responde:

Na história dos sete dias no n. 73 d'A Semana, Filintal, com o espirito fulgurante e inexgotavel que todos lhe conhecemos, falou da fundação, em Londres, da "Liga da Toilette Nacional".

Rematou as suas judiciosas reflexões, lembrando que é meu o encargo de falar em modas nestas colunas e eu apresso-me em obedecer á interpelação dizendo algumas palavras relativas á projectada revolução na elegância feminina (VIEIRA, A Semana a.2 n. 75, 05 de junho de 1886, p. 181).

Diferente do que a maioria das pessoas poderia achar, Filindal defende o fim das roupas exageradas das mulheres e é contra o uso do espartilho. Adelina Vieira concorda com as ideias da liga, mas, por fim, sugere o uso de vestimenta nas formas mais tradicionais para suas leitoras. Ela, como mulher, entendia que a viabilidade de as mulheres alterarem seu modo

\footnotetext{
17 "Filinto de Almeida assinou a sessão "História de Sete Dias" n’A Semana, com o pseudônimo Filindal" (SOUZA, 2016, p. 23).
} 


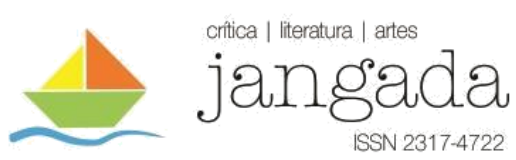

de vestir seria no mínimo demorado. Como os avanços em prol de direitos das mulheres ainda eram lentos e elas continuavam consideradas como eternas menores, Adelina Vieira não era capaz de defender o fim dos espartilhos da moda por estar ainda presa aos espartilhos sociais. Estavam todas sucumbidas à tirania moderna que torturava seus corpos. A não ser que esta fosse abolida, ou que se retornasse a um tempo no qual as vestimentas não aprisionavam o corpo, comentava Lopes Vieira, aproveitando o ensejo para ensinar algo sobre a história das mulheres, ironicamente sem descuidar da origem francesa como modelo de indumentária:

Algumas senhoras terão razão para oppor uma resistencia tenace aos decretos racionaes da Liga. Todos sabemos que muitos corpos desgraciosos conseguem arremedar a elegancia com o auxilio do espartilho: e claro está que o salto á Luiz XV parece diminuir consideravelmente os pés; mas a maior parte, (com certeza todas as leitoras d'A Semana), deformam-se por moda, e muito ganhariam em deixar admirar, libertas do espartilho, (instrumentos de tortura semi-selvagens) as suas formas ideaes.

Mas para supprimir os espartilhos, augmentando a elegancia, seria preciso remontarmos ao seculo $\mathrm{X}$, ao tempo dos Gaulezes, ás amplas e graciosas tunicas e chlamydes de linho, seda, purpura e ouro; aos longos e transparentes véus, como unico adorno sobre os cabellos soltos ou em tranças; ou mesmo a mais tarde, aos Merovingios, Carlovingios e Capetos, isto até aos principios do XIV seculo (porque em 1350 começaram a ser usados os cabellos postiços, a que se seguiram os vertugadins, as crinolines, os espartilhos, as collerettes, as moscas, etc., etc.) (VIEIRA, A Semana a.2 n. 75, 05 de junho de 1886, p. 181)

Em outra circunstância, uma leitora enviou carta pedindo que Adelina Lopes Vieira também tratasse de moda, argumentando que havia cancelado as assinaturas dos jornais desse gênero. Adelina responde que "a minha linda faceira fez mal em não renovar, as assignaturas dos jornaes de modas, principalmente os da Casa Nicoud" (VIEIRA, A Semana a.2 n. 71, 8 de maio de 1886, p. 148-149). A colunista ainda reclama de a leitora que enviara a carta ter aceitado muitos convites para eventos, conforme relatado na missiva, pois a escritora não daria conta de ajudá-la com todas aquelas vestimentas. 
A temática e a forma de abordagem de homens e mulheres sobre os assuntos eram diferentes e, com certeza, havia a necessidade de que assim o fossem. No entanto, há nas colunas de Adelina um nicho concreto de seu interesse que era a tentativa de ajudar as mulheres em seu bem estar. Assuntos como moda e festas, com os quais os homens as estereotipavam suspeitando serem seus únicos interesses, não se aproximavam da escrita de Adelina Lopes Vieira em A Semana. Além disso, é necessário levar em consideração o veículo no qual esses textos eram publicados, pois, lembrando o ensinamento de Chartier (1991), os leitores não se deparavam com textos abstratos separados de sua materialidade. Esse jornal não era voltado exclusivamente às mulheres, mas a um público majoritariamente masculino, com discussões políticas e sociais, cabendo à Adelina Vieira alcançar as leitoras, possivelmente as esposas e as filhas dos leitores. Logo, não era o meio ideal para ideias muito ameaçadoras da masculinidade e da família burguesa.

Se repararmos no poema "Desesperança", de onde retiramos duas estrofes para epígrafe deste texto, a mulher com "formas de estatua" e "o andar de uma duquesa", muito linda, inteligente e bem educada, assustava os homens. Ela acreditava ter sido amada, mas tinha sido ilusão. A arte, seu canto enquanto toca a harpa, era sua única companhia. Esse texto, também veiculado em A Semana, funciona tanto como instrução às leitoras, que precisariam ser modestas para não sofrerem essa vida de desesperança, quanto como alegoria para artistas como Adelina Amélia Lopes Vieira que encontravam na poesia sua confidente por serem mais do que os homens de seu tempo permitiam. São eles, no fundo, os apequenados nessa situação. Os últimos versos são: "Nada mais crê e espera na verdade./ Vê os homens que amara, tão pequenos!/ e... continuam a fitar, serenos/ os seus olhos azues a imensidade!!” (VIEIRA, $A$ Semana a. IV n.69-170, 21/04/1888, p. 82). Em uma sociedade de homens pequenos não há esperança para mulheres altivas com voz dominadora.

\section{ENTRE O CONTROLE E A EDUCAÇÃO PARA AS MULHERES}

Colunas como as "Palestras Femininas" parecem reforçar um perfil conservador para as vidas, as mentalidades e os corpos das mulheres, mostrando os cuidados com o lar, o marido e os filhos como suas ocupações preferenciais. Adelina Amélia Lopes Vieira, mesmo não se atendo a alguns assuntos destinados tipicamente às leitoras, como modas ou bailes, reforçava o estigma das mulheres que tinham suas vidas dedicadas ao ambiente doméstico. Tal modelo de escrita 


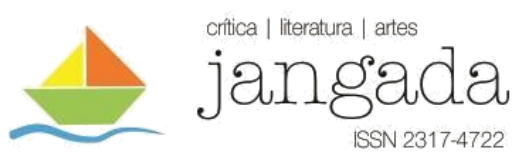

acompanha a obra da poetisa não apenas nessas colunas, mas também em seus contos, que funcionam partindo da mesma premissa. O conservadorismo da época era resultado da educação que aquelas mulheres recebiam. Porém, a despeito do seu perfil temático, Adelina tinha uma vida pública e uma profissão, longe de se restringir, portanto, ao ambiente doméstico preconizado em seus artigos.

Os texto da coluna "Palestras Femininas" seguem uma estética comum aos manuais de civilidade do século XIX, exaltam estereótipos das mulheres e têm a necessidade didática de ensinar como viver, como se comportar, como lidar com o marido e com os filhos. A autora não era obrigada a seguir exatamente esses modelos, mas provavelmente sua educação deve ter sido baseada em como reger uma família e sua casa. Sobretudo, o veículo de divulgação desses textos poderia impedir atitudes mais emancipadoras.

As representações de mulheres infelizes no matrimônio, inclusive com casos de adultério, tinham muito mais um caráter moralizador de perfis que não deveriam ser seguidos do que uma tentativa de criticar ou querer afirmar uma insubmissão. Era, na verdade, preciso reafirmar a possibilidade de ridicularização pública caso fizessem algo errado, ou da completa infelicidade caso não seguissem as ordens de um homem.

O controle do patriarcado exerceu durante muitos anos um caráter dominador que oprimiu as mulheres durante muitas gerações. As do século XIX não eram ensinadas a terem a possibilidade de pensar diferente. Mesmo textos de escritoras acabavam por reforçar essa dominação, como apresentamos no caso de Adelina Vieira. Dessa forma, podemos afirmar que Adelina Lopes Viera, em suas "Palestras Femininas", era uma mulher conservadora, mas também podemos entender que esse conservadorismo advinha do seu contexto social e do que era esperado e permitido que ela escrevesse nesse jornal. As leitoras precisavam achar em seus textos um reduto de conforto e não de descontrole. Esperava-se que pudessem encontrar formas de melhor viver dentro da realidade existente, com aplicabilidade prática.

Apesar disso, ao defender muitas vezes a educação das mulheres e das crianças, Adelina Amélia Lopes Vieira indicava caminhos futuros de autonomia. Ainda poderia estar longe o tempo de abolição dos espartilhos sociais, mas algo em seus textos parecia preparar as mulheres para esse tempo que viria. Além disso, seu exemplo como educadora e escritora pública deve ter também educado ou motivado muitas de suas leitoras e admiradoras, como a própria irmã. 


\section{REFERÊNCIAS BIBLIOGRÁFICAS}

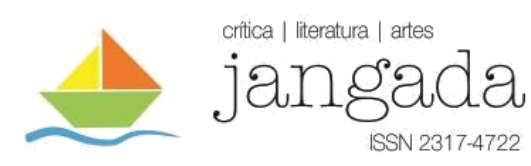

ARIÈS, Philippe. História social da criança e da família. Rio de Janeiro: Zahar Editores, 1973. ANASTÁCIO, V. Almanaques: origem, géneros, produção feminina. In: Veredas: Revista da Associação Internacional de Lusitanistas, n. 18, p. 53-74, 1 dez. 2012. Disponível em: https://revistaveredas.org/index.php/ver/article/view/63 Acesso em 28/10/2020.

ANDRADE, Maria Celeste de Moura. O século XIX: O mundo burguês / O casamento/A nova mulher: O contexto histórico dos romances Madame Bovary, Ana Karenina, O Primo Basílio e Dom Casmurro. In: Evidência, Araxá, v. 8, n. 9, p. 63-80, 2013.

BOURDIEU, Pierre. A dominação masculina. 12a ed. Rio de Janeiro: Bertrand Brasil, 2014.

CERNIC RAMOS, Ana Flávia. Escravidão e cidadania nas páginas da revista A Semana de Valentim Magalhães (1885). Rio de Janeiro: Ampuh, 2012.

CHARTIER, Roger. O Mundo como representação. In: Estudos Avançados 11(5), São Paulo: 1991. Disponível em: http://www.revistas.usp.br/eav/article/view/8601/10152.

CUNHA, Ana Cristina Comandulli da. Presença de A. F. de Castilho nas Letras Oitocentistas Portuguesas: sociabilidades e difusão da escrita feminina. Tese (Doutorado em Literatura Comparada) Niterói: Universidade Federal Fluminense, 2014.

DA CRUZ, Eduardo. Um "brilhante congresso": escritoras portuguesas no projeto de António Feliciano de Castilho para sua versão d'Os Fastos ovidianos. In: SOLETRAS, [S.1.], n. 34, p. 140-164, nov. 2017. ISSN 2316-8838. Disponível em: https://www.epublicacoes.uerj.br/index.php/soletras/article/view/30436. Acesso em: 28 out. 2020. doi:https://doi.org/10.12957/soletras.2017.30436.

FILINDAL (pseud.. de ALMEIDA, Filinto de), "História de Sete Dias", A Semana a.2 n. 73, 22 de maio de 1886, p. 1-2

DUARTE, Constância Lima. Imprensa feminina e feminista no brasil: século xix - dicionário ilustrado. Belo Horizonte: Autêntica, 2016.

LIMA, Nísia Trindade, HOCHMAN, Gilberto. Condenado pela raça, absolvido pela medicina:

O Brasil descoberto pelo movimento sanitarista da Primeira República. In: MAIO, Marcos Chor, SANTOS, Ricardo Ventura (Orgs.). Raça, ciência e sociedade. Rio de Janeiro: Fiocruz, Centro Cultural Banco do Brasil, 1996.

MANCHOPE, Elenita. Entre narrativas e imagens: trilhando passos. In: Revista de Literatura história e memória, Cascavel, v. 12, n.19, p. 143-166, 2016.

Jangada | nr. 16, jun/dez, 2020 | ISSN 2317-4722

62 | Pá g in a 


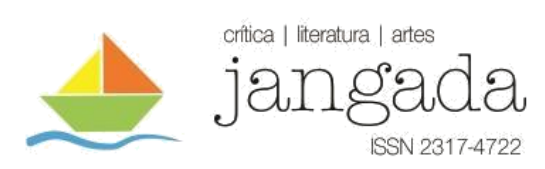

MORÃO, Paula. As infinitamente delicadas coisas do espírito. Notas sobre a poética de Irene Lisboa. In: $O$ secreto e o real. Ensaios sobre literatura portuguesa. Lisboa: Campo da Comunicação, 2011.

PASSETI, Edson. O menor no Brasil Republicano. In: DEL PRIORE, Mary. (org.) História da criança no Brasil. 3. ed. São Paulo: Contexto, 1995

RAFAEL, Gina Guedes. A leitura feminina na segunda metade do século XIX em Portugal: testemunhos e problemas. Trabalho de Projeto (Mestrado em Edição de Texto) - Faculdade de Ciências Sociais e Humanas, Universidade Nova de Lisboa, Lisboa, 2011.

S. A.. A festa das creanças - Comemoração da Lei de 13 de maio que aboliu a escravidão no Brazil. Rio de Janeiro: Imprensa Nacional, 1888.

SANTOS, Maria de Lourdes dos. Para uma sociologia da cultura burguesa em Portugal no século XIX. Lisboa: Editorial presença, 1983.

VAQUINHAS, Irene. "Senhoras e mulheres" na sociedade portuguesa do século XIX. Lisboa: Colibri 2012.

VIEIRA, Adelina Lopes. "Desesperança". A Semana a.IV n. 69-170, 21/04/1888, p. 82

VIEIRA, Adelina Lopes. "Palestras femininas - Chopin". A Semana a.II n.70, 01/05/1886, p. 139

VIEIRA, Adelina Lopes. "Palestras femininas - Modas". A Semana a.II n. 71, 08/05/1886, p. $148-149$

VIEIRA, Adelina Lopes. "Palestras femininas - O lar". A Semana a.II n. 72, 15/05/1886, p. 156 VIEIRA, Adelina Lopes. "Palestras femininas - Liga da 'Toilette' Nacional(*)". A Semana a.II n. $75,05 / 06 / 1886$, p. 181-182

VIEIRA, Adelina Lopes. "Palestras femininas - Pedagogia infantil". A Semana a.II n. 77, 19/06/1886, p. 194-195

VIEIRA, Adelina Lopes. "Palestras femininas - As flores". A Semana a.II n. 79, 03/07/1886, p. 214

VIEIRA, Adelina Lopes. "Palestras femininas - A noiva". A Semana a.II n. 82, 24/07/1886, p. 238

VIEIRA, Adelina Lopes. "Palestras femininas - Pedagogia infantil". A Semana a.II n. 86, 21/08/1886, p. 270-271

VIEIRA, Adelina Lopes. "Palestras femininas - Futuros". A Semana a.II n. 89, 11/09/1886, p. 294-295

Jangada | nr. 16, jun/dez, 2020 | ISSN 2317-4722

63 | Pá g in a 
VIEIRA, Adelina Lopes. "Palestras femininas - Dores". A Semana a.II n. 92, 02/10/1886, p. 320-321

VIEIRA, Adelina Lopes. "Palestras femininas - Amor conjugal". A Semana a.II n. 94, 16/10/1886, p. $335-336$

VIEIRA, Adelina Lopes. "Palestras femininas - Pedagogia infantil". A Semana a.II n. 99, 20/11/1886, p. 375-376

VIEIRA, Adelina Lopes. "Palestras femininas - Renascimento". A Semana a.III n. 121, 23/04/1887, p. 375-376

VIEIRA, Adelina Lopes. "Palestras femininas". A Semana a.III n. 129, 18/06/1887, p. 195

VIEIRA, Adelina Lopes. "Palestras femininas". A Semana a.III n. 134, 23/07/1887, p. 236 -195

VIEIRA, Adelina Lopes. "Palestras femininas - visões". A Semana a.III n. 145-146, 14/10/1887, p. 323

\section{Periódicos consultados}

A Mensageira, a.1 n.2, 30 de outubro de 1897, p. 31

Gazeta de Campinas, a. I n. 17, 25 de dezembro de 1869, p. 2

Gazeta de Notícias, a. 2 n. 176, 27 de julho de 1871, p. 2

O Portuguez, a.III n. 13, 12 de fevereiro de 1863, p. 4

Portugal Moderno, a. VI n. 281, 29 de abril de 1905, p. 2

A Semana a. II-III, 1886-1887 